\title{
Icteric Index
}

National Cancer Institute

\section{Source}

National Cancer Institute. Icteric Index. NCI Thesaurus. Code C111232.

The determination of the amount of yellow color of a biological specimen, due to the presence of bile pigments. 